\title{
Cilengitide combined with standard treatment for patients with newly diagnosed glioblastoma with methylated MGMT promoter (CENTRIC EORTC 26071-22072 study): a multicentre, randomised, open-label, phase 3 trial
}

\author{
Stupp, R ; Hegi, M E ; Gorlia, T ; et al ; Kim, C Y ; Nabors, L B ; Reardon, D A ; van den Bent, M J ;
} Hicking, C ; Markivskyy, A ; Picard, M ; Weller, M

\begin{abstract}
BACKGROUND Cilengitide is a selective v 3 and v 5 integrin inhibitor. Data from phase 2 trials suggest that it has antitumour activity as a single agent in recurrent glioblastoma and in combination with standard temozolomide chemoradiotherapy in newly diagnosed glioblastoma (particularly in tumours with methylated MGMT promoter). We aimed to assess cilengitide combined with temozolomide chemoradiotherapy in patients with newly diagnosed glioblastoma with methylated MGMT promoter. METHODS In this multicentre, open-label, phase 3 study, we investigated the efficacy of cilengitide in patients from 146 study sites in 25 countries. Eligible patients (newly diagnosed, histologically proven supratentorial glioblastoma, methylated MGMT promoter, and age 18 years) were stratified for prognostic Radiation Therapy Oncology Group recursive partitioning analysis class and geographic region and centrally randomised in a 1:1 ratio with interactive voice response system to receive temozolomide chemoradiotherapy with cilengitide $2000 \mathrm{mg}$ intravenously twice weekly (cilengitide group) or temozolomide chemoradiotherapy alone (control group). Patients and investigators were unmasked to treatment allocation. Maintenance temozolomide was given for up to six cycles, and cilengitide was given for up to 18 months or until disease progression or unacceptable toxic effects. The primary endpoint was overall survival. We analysed survival outcomes by intention to treat. This study is registered with ClinicalTrials.gov, number NCT00689221. FINDINGS Overall, 3471 patients were screened. Of these patients, 3060 had tumour MGMT status tested; 926 patients had a methylated MGMT promoter, and 545 were randomly assigned to the cilengitide $(n=272)$ or control groups $(n=273)$ between Oct 31,2008 , and May 12, 2011. Median overall survival was 26•3 months (95\% CI 23•8-28•8) in the cilengitide group and $26 \bullet 3$ months $(23 \bullet 9-34 \bullet 7)$ in the control group (hazard ratio $1 \bullet 02,95 \%$ CI $0 \bullet 81-1 \bullet 29$, $\mathrm{p}=0 \bullet 86)$. None of the predefined clinical subgroups showed a benefit from cilengitide. We noted no overall additional toxic effects with cilengitide treatment. The most commonly reported adverse events of grade 3 or worse in the safety population were lymphopenia (31 [12\%] in the cilengitide group vs $26[10 \%]$ in the control group), thrombocytopenia (28 [11\%] vs $46[18 \%])$, neutropenia (19 [7\%] vs 24 $[9 \%])$, leucopenia $(18[7 \%]$ vs $20[8 \%])$, and convulsion (14 [5\%] vs $15[6 \%])$. INTERPRETATION The addition of cilengitide to temozolomide chemoradiotherapy did not improve outcomes; cilengitide will not be further developed as an anticancer drug. Nevertheless, integrins remain a potential treatment target for glioblastoma. FUNDING Merck KGaA, Darmstadt, Germany.
\end{abstract}

DOI: https://doi.org/10.1016/S1470-2045(14)70379-1 
Journal Article

Accepted Version

Originally published at:

Stupp, R; Hegi, M E; Gorlia, T; et al; Kim, C Y; Nabors, L B; Reardon, D A; van den Bent, M J; Hicking, C; Markivskyy, A; Picard, M; Weller, M (2014). Cilengitide combined with standard treatment for patients with newly diagnosed glioblastoma with methylated MGMT promoter (CENTRIC EORTC 26071-22072 study): a multicentre, randomised, open-label, phase 3 trial. Lancet Oncology, 15(10):11001108.

DOI: https://doi.org/10.1016/S1470-2045(14)70379-1 


\section{Cilengitide combined with standard treatment for patients with newly diagnosed glioblastoma with methylated $0^{6}$-methylguanine-DNA methyltransferase (MGMT) promoter: final results of the multicentre, randomised, open-label, controlled, phase 3 CENTRIC (EORTC 26071-22072) study}

Prof Roger Stupp, MD, ${ }^{1,2}$ Monika E. Hegi, PhD, ${ }^{2}$ Thierry Gorlia, PhD, ${ }^{3}$ Sara C. Erridge, MD, ${ }^{4}$ James Perry, MD, ${ }^{5}$ Prof Yong-Kil Hong, MD, ${ }^{6}$ Kenneth D. Aldape, MD, ${ }^{7}$ Benoit Lhermitte, MD, ${ }^{2}$ Prof Torsten Pietsch, MD, ${ }^{8}$ Prof Danica Grujicic, MD, ${ }^{9}$ Prof Joachim Peter Steinbach, MD, ${ }^{10}$ Prof Wolfgang Wick, MD, ${ }^{11}$ Prof Rafał Tarnawski, MD, ${ }^{12}$ Prof Do-Hyun Nam, MD, ${ }^{13}$ Prof Peter Hau, MD, ${ }^{14}$ Astrid Weyerbrock, MD, ${ }^{15}$ Prof Martin JB Taphoorn, MD, ${ }^{16}$ Chiung-Chyi Shen, MD, ${ }^{17}$ Nalini Rao, MD, ${ }^{18}$ László Thurzo, MD, ${ }^{19}$ Ulrich Herrlinger, MD, ${ }^{8}$ Tejpal Gupta, MD, ${ }^{20}$ Prof Rolf-Dieter Kortmann, MD, ${ }^{21}$ Krystyna Adamska, MD, ${ }^{22}$ Catherine McBain, MD, ${ }^{23}$ Alba A. Brandes, MD, ${ }^{24}$ Prof Joerg Christian Tonn, MD, ${ }^{25}$ Oliver Schnell, MD, ${ }^{25}$ Prof Thomas Wiegel, MD, ${ }^{26}$ Chae-Yong Kim, MD, ${ }^{27}$ Louis Burt Nabors, MD, ${ }^{28}$ David A. Reardon, $\mathrm{MD}^{29}$ Prof Martin J. van den Bent, MD, ${ }^{30}$ Christine Hicking, MSc, ${ }^{31}$ Andriy Markivskyy, MD, ${ }^{31}$ Martin Picard, PhD, ${ }^{31}$ and Prof Michael Weller, MD, ${ }^{1}$ on behalf of European Organisation for Research and Treatment of Cancer (EORTC), the Canadian Brain Tumor Consortium, and the CENTRIC study team.

${ }^{1}$ UniversitätsSpital Zürich, Zurich, Switzerland; ${ }^{2}$ Centre Hospitalier Universitaire Vaudois and University of Lausanne, Lausanne, Switzerland; ${ }^{3}$ EORTC Data Centre, Brussels, Belgium; ${ }^{4}$ Edinburgh Cancer Centre, University of Edinburgh, Edinburgh, UK; ${ }^{5}$ Sunnybrook Health Sciences Centre, Toronto, ON, Canada; ${ }^{6}$ The Catholic University of Korea, Seoul St. Mary's Hospital, Seoul, Korea; ${ }^{7}$ The University of Texas MD Anderson Cancer Center, Houston, TX, USA; ${ }^{8}$ Universität Bonn, Bonn, Germany; ${ }^{9}$ Clinic for Neurosurgery, Clinical Center Serbia and Medical Faculty University of Belgrade, Belgrade, Serbia; ${ }^{10}$ Klinikum der J.W. Goethe Universität Frankfurt, Frankfurt, Germany; ${ }^{11}$ Heidelberg University Medical Center \& German Cancer Research Center, Heidelberg, Germany; ${ }^{12}$ Maria Sklodowska-Curie Memorial Cancer Center and Institute of Oncology Gliwice Branch, Gliwice, Poland; ${ }^{13}$ Samsung Medical Center, Sungkyunkwan Univ School of Medicine, Seoul, Korea; ${ }^{14}$ Universitätsklinikum Regensburg, Regensburg, Germany; ${ }^{15}$ Universitätsklinikum Freiburg, Freiburg, Germany; ${ }^{16}$ Medical Center Haaglanden, The Hague, The Netherlands; ${ }^{17}$ Taichung Veterans General Hospital, Taichung, Taiwan; ${ }^{18}$ Bangalore Institute of Oncology, Bangalore, India; ${ }^{19}$ Szegedi Tudományegyetem, Szeged, Hungary; ${ }^{20}$ Tata Memorial Centre, Navi Mumbai, India; ${ }^{21}$ Universitätsklinikum Leipzig, Leipzig, Germany; ${ }^{22}$ Greater Poland Cancer Centre, Poznań, Poland; ${ }^{23}$ The Christie NHS FT, Manchester, UK; ${ }^{24}$ Medical Oncology Department, AUSL - IRCCS Institute of Neurological Sciences, Bologna, Italy; ${ }^{25}$ Klinikum der Universität München, München, Germany; ${ }^{26}$ University Hospital Ulm, Ulm, Germany; ${ }^{27}$ SNU Bundang Cancer 
Hospital, Seoul, South Korea, Korea; ${ }^{28}$ University of Alabama at Birmingham, Birmingham, AL, USA; ${ }^{29}$ DanaFarber Cancer Institute, Boston, MA, USA; ${ }^{30}$ Erasmus MC-Cancer Institute, Rotterdam, The Netherlands; ${ }^{31}$ Merck KGaA, Darmstadt, Germany.

Corresponding author: Professor Roger Stupp

Address: Department of Oncology, University Hospital Zurich, Raemistrasse 100, 8091 Zurich, Switzerland

Phone: +41442559779

Fax: $\quad+41442559780$

Email: Roger.Stupp@usz.ch

Word count (body of the manuscript): 3459

Reference count: 33 


\section{Abstract}

Background: Cilengitide is a selective $\alpha v \beta 3$ and $\alpha v \beta 5$ integrin inhibitor. Phase 2 trial data suggested antitumour activity of cilengitide as a single agent in recurrent glioblastoma and in combination with standard temozolomide (TMZ) chemoradiotherapy (TMZ/RT $\rightarrow T M Z$ ) in newly diagnosed glioblastoma, particularly in tumours with methylated MGMT promoter.

Methods: This multicentre, open-label, phase 3 study (NCT00689221) investigated the efficacy of cilengitide in patients with newly diagnosed, histologically proven supratentorial glioblastoma with methylated MGMT status. After stratification for prognostic Radiation Therapy Oncology Group recursive partitioning analysis class and geographic region, patients were centrally randomised 1:1 to receive $T M Z / R T \rightarrow T M Z$ with cilengitide 2000 mg i.v. twice-weekly (cilengitide arm) or TMZ/RT $\rightarrow T M Z$ alone (control arm). Maintenance TMZ was given for up to 6 cycles, cilengitide was administered for up to 18 months, or until disease progression or unacceptable toxicity. The primary endpoint was overall survival. Secondary endpoints included progression-free survival (PFS), and safety. Outcome was analysed on intent-to-treat basis.

Findings: Overall, 3471 patients were screened. Of these, 3060 had tumour MGMT status tested; 926 patients had a methylated MGMT promoter, of which 545 patients (median age, 58 years) were randomised to cilengitide $(n=272)$ or control arm $(n=273)$. Median survival was $26 \cdot 3$ months in both arms (HR, 1.02; 95\% Cl, 0.81-1.29; $\mathrm{p}=0 \cdot 86)$. PFS assessed by the Independent Review Committee was 10.6 months in the cilengitide arm and 7.9 months in the control arm $(\mathrm{HR}, 0.92 ; 95 \% \mathrm{Cl}, 0.75-1.12$; $\mathrm{p}=0.41$ ). Investigator assessed PFS was 13.5 months in the cilengitide arm and 10.7 months in the control arm (HR, 0.93; 95\% Cl, 0.76-1.13; $\mathrm{p}=0.46)$. None of the predefined clinical subgroups showed a benefit from cilengitide. Treatment was generally well tolerated, no added toxicity was observed with cilengitide. Most commonly reported $(>5 \%)$ grade $\geq 3$ adverse events in the cilengitide and control arm, respectively, included lymphopaenia ( $n=31$ vs $n=26$ ), thrombocytopaenia ( $n=28$ vs $n=46)$; neutropaenia ( $n=19$ vs $n=24)$, leukopaenia ( $n=18$ vs $n=20)$, and convulsion ( $n=14$ vs $n=15)$. 
Interpretation: The addition of cilengitide to standard TMZ/RT $\rightarrow T M Z$ did not improve outcome and cilengitide will not be further developed as an anticancer agent. Nevertheless, integrins remain a potential treatment target for glioblastoma.

Funding: Merck KGaA, Darmstadt, Germany. 


\section{Introduction}

Glioblastoma is the most common histological subtype of primary malignant brain tumours, with an annual incidence of approximately $3 / 100,000 .{ }^{1}$ Glioblastomas are also the most aggressive form of primary brain tumours, with a dismal median survival $<12$ months in population-based studies, and median survival of 15-17 months in clinical trials. ${ }^{2-4}$ The current standard treatment for patients with newly diagnosed glioblastoma consists of surgery followed by radiotherapy with concomitant and adjuvant temozolomide (TMZ/RT $\rightarrow \mathrm{TMZ}) \cdot{ }^{2,5}$ Other chemotherapy agents demonstrated little activity due to inherent resistance of glioblastoma cells against most cytotoxic agents, or the inability of the agents to cross an intact blood-brain barrier and reach their target. ${ }^{6,7}$

The DNA repair protein $0^{6}$-methylguanine-DNA methyltransferase (MGMT) is an important prognostic factor in glioblastoma; its presence has been associated with inferior survival and resistance to alkylating chemotherapy. ${ }^{8}$ Epigenetic silencing of the MGMT gene by promoter methylation may lead to it subsequently being unable to protect tumours from cytotoxic damage induced by $\mathrm{TMZ}$ and thus predict benefit from TMZ chemotherapy. ${ }^{9}$ In a pivotal randomised trial investigating the value of TMZ added to RT in patients with glioblastoma, median survival in patients with methylated MGMT promoter was increased from 15.3 months with RT alone to 21.7 months with RT and TMZ. ${ }^{10}$ However, patients with unmethylated MGMT promoter in the tumour showed only a marginal benefit from RT and TMZ treatment, with a median survival of $12.7 \mathrm{vs} 11.8$ months.

Although glioblastomas very rarely metastasise, local recurrence at the edge of resection but also at distant locations within the brain is frequent. Glioblastoma cells are characterised by high motility and invasiveness, requiring complex cell-matrix interactions. ${ }^{11}$ Integrins are a family of cell-cell and cell-extracellular matrix adhesion molecules, involved in a variety of cellular processes, such as cell survival, proliferation, migration, invasion, and angiogenesis, and thus can support tumour development. ${ }^{12}$ In particular $\alpha v \beta 3$ and $\alpha v \beta 5$ integrins are considered key mediators of crosstalk between tumour cells and the brain microenvironment in glioblastoma and are overexpressed on 
tumour cells and vasculature. ${ }^{13-15}$ Therefore, targeting integrins and the tumour microenvironment is considered a promising therapeutic strategy in glioblastoma. ${ }^{15,16}$

Cilengitide is a selective inhibitor of $\alpha v \beta 3$ and $\alpha v \beta 5$ integrins. ${ }^{17}$ In phase $1 / 2$ studies in patients with recurrent or newly diagnosed glioblastoma, cilengitide alone or in combination with $T M Z / R T \rightarrow T M Z$ was well tolerated and showed potential antitumour activity. ${ }^{18-22}$ In a multicentre phase $1 / 2$ study of cilengitide added to standard TMZ/RT $\rightarrow T M Z$ in patients with newly diagnosed glioblastoma, survival analyses indicated improved outcome compared with historical controls in patients with methylated MGMT gene promoter in the tumour, suggestive of synergy between cilengitide and TMZ chemotherapy in chemosensitive tumours. ${ }^{20}$ Patients with and without MGMT promoter methylation had median progression-free survival (PFS) of 13.4 and 3.4 months, and a median overall survival of 23.2 and 13.1 months, respectively. ${ }^{20}$ Furthermore, two randomised phase 2 studies demonstrated improved survival for glioblastoma patients treated with higher (2000 mg) versus lower $(500 \mathrm{mg})$ dose of cilengitide, in both the newly diagnosed and recurrent setting. ${ }^{19,21}$ Preclinical models also demonstrated synergistic activity of cilengitide and irradiation. ${ }^{23}$ Thus, we embarked on the randomised phase 3 trial reported here, restricting eligibility to a subgroup of patients with glioblastoma with methylated MGMT promoter. The investigation of patients with an unmethylated MGMT promoter in the tumour was subject of an exploratory phase 2 study (CORE) initiated shortly after CENTRIC. ${ }^{24}$ 


\section{Methods}

\section{Study design and treatment}

This was a global, multicentre, randomised, controlled, open-label, phase 3 study (NCT00689221). Patients were recruited at over 200 study sites in 25 countries worldwide. Prior to randomisation and after informed consent, an independent pathology review was performed and MGMT promoter methylation status of the tumour was centrally determined by licensed laboratories of MDxHealth (Herstal, Belgium) using quantitative methylation-specific polymerase chain reaction (PCR) basically as described previously. ${ }^{25}$ In brief, DNA was isolated from formalin-fixed, paraffin-embedded tumour samples using macro-dissected sections; DNA was modified with sodium bisulfite and subjected to methylation-specific PCR using ß-actin as a reference gene (ACTB). Patients were considered MGMT methylated when the ratio of MGMT to ACTB was 2.0 or more, calculated as (methylated $M G M T / A C T B) \times 1000$; the cut-off corresponding to the established nadir that separates methylated from unmethylated. ${ }^{26} \mathrm{~A}$ minimum of 1250 copies of $A C T B$ were required for a valid result, unless the copy number for methylated MGMT was ten or more, which was scored as MGMT methylated.

Eligible patients were subsequently randomly assigned $1: 1$ to receive either standard TMZ/RT $\rightarrow T M Z$ alone, or with added cilengitide (standard dose of $2000 \mathrm{mg}$ i.v. twice weekly on Days 1 and 4, beginning at week 1$)^{3}$ (Figure 1). RT consisted of 3D conformal RT and was given at 2 Gy per fraction, 5 days/week, for up to 6 weeks and a total of $60 \mathrm{~Gy}$; TMZ $75 \mathrm{mg} / \mathrm{m}^{2}$ was administered orally 7 days/week throughout RT, thereafter, starting 4 weeks after the end of RT (week 11) TMZ 150-200 $\mathrm{mg} / \mathrm{m}^{2}$ was administered for 5 consecutive days every 4 weeks for 6 cycles. ${ }^{3}$ Cilengitide was to be continued for up to 18 months or until disease progression (PD) or unacceptable toxicity. In case of first occurrence of an unacceptable toxicity considered as study drug-related, cilengitide treatment was to be suspended until recovery from the adverse event ( $A E)$ to grade $\leq 2$. Thereafter, administration could be restarted at the investigator's discretion at a dose of $500 \mathrm{mg}$, and gradually increased in weekly intervals up to $2000 \mathrm{mg}$. Cilengitide treatment was to be discontinued 
permanently if the same severe toxicity recurred. Crossover from the control to the cilengitide arm was not allowed. Cilengitide was administered as 1-hour i.v. infusion starting 4 hours before RT; TMZ was given orally within 2 hours after completion of cilengitide infusion and at least 1 hour before RT. The study was conducted in accordance with the Declaration of Helsinki, the International Conference on Harmonisation note for good clinical practice (Topic E6, 1996), and applicable regulatory requirements. Study protocol and patient information sheet were approved by the Institutional Review Boards or Independent Ethics Committees of the participating institutions and competent authorities according to country-specific regulations.

\section{Randomisation and masking}

Randomisation (1:1) was performed centrally using an interactive voice response system. Patients were stratified in blocks according to geographic region (ie, Europe, North America, and Rest of World) and Radiation Therapy Oncology Group recursive partitioning analysis class. As this was an open-label study, no blinding procedures were applied.

\section{Key patient eligibility criteria}

Patients aged $\geq 18$ years with newly diagnosed, histologically confirmed supratentorial glioblastoma (WHO Grade IV), centrally determined methylated MGMT status, and with an Eastern Cooperative Oncology Group performance status (ECOG PS) of 0 or 1 were eligible. Additional inclusion criteria were: written informed consent; available tumour tissue from surgery or open biopsy (stereotactic biopsy was not allowed) for MGMT promoter methylation status analysis and central pathology review; gadolinium-enhanced (Gd) MRI performed within 48 hours postsurgery, or alternatively, GdMRI performed before randomisation; stable or decreasing steroid doses for $\geq 5$ days prior to randomisation; and adequate haematological, renal, and liver function. Key exclusion criteria were prior chemotherapy within the last 5 years, prior RT of the head (except for low-dose RT for tinea capitis), treatment with other investigational agents 30 days before first dose of cilengitide, and prior systemic antiangiogenic therapy; history of coagulation disorder associated with bleeding or 
recurrent thromboembolic events; placement of carmustine wafers (Gliadel ${ }^{\circledast}$ ) at surgery; history of malignancy within the last 5 years (except curatively treated cervical carcinoma in situ or basal cell carcinoma of the skin); clinically manifest cardiovascular insufficiency (NYHA III, IV) or history of myocardial infarction during the past 6 months, and uncontrolled arterial hypertension.

\section{Study endpoints}

The primary endpoint was overall survival. Secondary endpoints included PFS and safety.

\section{Outcome measures and statistical analyses}

Overall survival was defined as time from randomisation until death; PFS was defined as duration from randomisation until first observation of PD or death from any cause. PFS was assessed locally by investigators based on Gd-MRI and according to the Macdonald criteria 4 weeks after RT, and 18, 26, and 34 weeks after randomisation as well as every 12 weeks thereafter during the follow-up phase. In case of suspected pseudoprogression investigators were advised to continue treatment per protocol and repeat imaging after 1-2 months. All imaging was reviewed at the end of study recruitment by an Independent Review Committee in a blinded manner. For this external review the recently (after this study's protocol initiation) developed and recommended Response Assessment in Neuro-Oncology (RANO) rather than the Macdonald criteria were used. ${ }^{27}$ Overall survival and PFS were estimated using the Kaplan-Meier method. Treatment arms were compared using log-rank test stratified for randomisation strata. A Cox proportional hazards model with stratification according to randomisation strata was used to calculate treatment $\mathrm{HR}$ and $95 \% \mathrm{Cls}$. No check of proportional hazards $(\mathrm{PH})$ assumptions was planned per protocol. Sensitivity analyses were performed unstratified and for the per-protocol set.

AEs were coded according to the Medical Dictionary for Regulatory Activities version $15 \cdot 0$, and their severity graded according to National Cancer Institute Common Terminology Criteria for Adverse Events version 3.0. All outcome analyses were performed on the intention-to-treat (ITT) population; 
safety was assessed on patients treated with at least one dose of cilengitide or who were exposed to RT or TMZ (safety population).

The study sample size was based on the assumption of a median overall survival of 23 months for the control group, a hazard ratio (HR) for the difference in overall survival between the experimental and control arms of 0.71 , power of $80 \%$, two-sided significance level of $5 \%$, and accrual of 24 months. Based on these assumptions, the target number of events was 266 , expected after 21 month followup, and planned sample size was 504 patients or 252 patients per arm. One formal interim analysis for futility was planned after observing $25 \%$ of planned maximal number of events. All statistical analyses were independently performed on mature data with a median follow-up of 29 months (interquartile range [IQR], 25-35 months) by both statisticians at Merck KGaA, Darmstadt, Germany, and at the European Organisation for Research and Treatment of Cancer (EORTC) using SAS ${ }^{\circledR}$ software version 9.1 or later.

Role of the funding source

This study was funded by Merck KGaA, Darmstadt, Germany. Study design, data analysis, and data interpretation were performed collaboratively by the principal investigators, EORTC, and the Merck study team. The Steering Committee oversaw the study. The principal investigators (RS, MW) had full access to and reviewed all data, and had final responsibility for the decision to submit for publication. Data collection was performed by a clinical research organisation; the database remained blinded to primary outcome variables for all parties until final analysis. 


\section{Results}

Overall, 3471 patients were registered and screened for eligibility; of these, 3060 patients were assessed for MGMT methylation status. A total of 926 patients were found to have glioblastoma with MGMT gene promoter methylation, including 382 patients who did not to continue to randomisation for reasons as depicted in Figure 2. A total of 545 patients were randomised from October 2008 through May 2011 and constituted the ITT population: 272 patients were scheduled to receive cilengitide twice-weekly in addition to standard TMZ/RT $\rightarrow T M Z$ (cilengitide arm) and 273 were to receive $T M Z / R T \rightarrow T M Z$ alone (control arm). The median duration from operation or biopsy to randomisation was 4.4 weeks (IQR, 3.7-5.4 weeks); the median time from surgery to start of RT was 6.2 weeks (IQR, 5.3-7.0 weeks) in the cilengitide arm and 5.4 weeks (IQR, 4.6-6.1 weeks) in the control arm (cilengitide treatment was to begin one week before RT). Patient baseline and demographic characteristics were well balanced across treatment arms; they are summarised in Table 1. Overall, 263 patients in the cilengitide arm, and 258 patients in the control arm, received at least one dose of study medication (safety population). The main reasons for discontinuing treatment in the cilengitide arm were PD (n=157), AE ( $n=22)$, and other $(n=54)$, and in the control arm, PD ( $n=153), A E(n=26)$, and other $(n=57)$. A total of 152 and 151 patients in the cilengitide and the control arm, respectively, received a further line of therapy following documented PD

\section{(Supplementary Table 1).}

Patients in the cilengitide arm (safety population) received cilengitide for a mean ( \pm SD) of 55.6 $( \pm 41.6)$ weeks, with a mean dose intensity of $3782( \pm 481) \mathrm{mg} /$ week; 216 patients $(82 \%)$ received $\geq 90 \%$ of the planned cilengitide dose. Overall, 237 patients $(90 \%)$ in the cilengitide arm received $\geq 90 \%$ of the planned TMZ dose, comparable to 237 patients (92\%) in the control group. Furthermore, 199 and 197 patients (76\% and 76\%) received $\geq 90 \%$ of the planned dose of RT, in the cilengitide and control arms, respectively. 
Median overall survival was $26 \cdot 3$ months $(95 \% \mathrm{Cl}, 24-29)$ in the cilengitide arm and $26 \cdot 3$ months (95\% Cl, 24-35) in the control arm (282 deaths; $\mathrm{HR}, 1 \cdot 02 ; 95 \% \mathrm{Cl}, 0.81-1 \cdot 29 ; \mathrm{p}=0 \cdot 86$; Figure 3A). The 2-year survival rate did not differ between treatment arms (56\% in both; $95 \% \mathrm{Cl}, 49 \%-61 \%$ for the cilengitide arm, $49 \%-62 \%$ for the control arm). Overall survival was similar in the two treatment arms irrespective of stratification according to baseline demographic characteristics and prognostic factors (Figure 3B). Median PFS as assessed by the investigator was $13 \cdot 5$ months $(95 \% \mathrm{Cl}, 10 \cdot 8-15 \cdot 9)$ in the cilengitide arm and 10.7 months $(95 \% \mathrm{Cl}, 8 \cdot 1-13 \cdot 3)$ in the control arm (388 PFS events; HR, 0.93; $95 \% \mathrm{Cl}, 0.76-1.13 ; p=0.46$; Figure $4 \mathrm{~A})$. The independent radiological review committee determined progression on average one assessment time point earlier in both arms, with a median of PFS 10.6 months $(95 \% \mathrm{Cl}, 8 \cdot 2-13.4)$ and 7.9 months $(95 \% \mathrm{Cl}, 5.9-12.5)$, respectively, in the cilengitide arm and control arm (389 PFS events; HR, 0.92; 95\% Cl, 0.75-1.12; $\mathrm{p}=0.41$; Figure 4B). Additionally, no benefit was observed in overall survival or PFS in the predefined patient subgroups with the addition of cilengitide to TMZ/RT $\rightarrow T M Z$.

Safety

Almost all patients experienced some treatment-emergent AEs (TEAEs) (Supplementary Table 2). Grade 3 or 4 TEAEs were observed in over half the patients, but there was no difference between the treatment arms (169 patients [64\%] in the cilengitide arm and 158 [61\%] in the control arm). The most common TEAEs (any grade and grade $\geq 3$ ) are summarised in Table 2. Grade 3 or 4 thromboembolic events occurred more frequently in the cilengitide arm (35 patients [13\%]) compared with the control arm (23 patients [9\%]), but still within the expected range. Grade 3 or 4 haemorrhages were similar in both arms (4 patients [2\%] each per arm). At least one serious AE was reported by 138 patients (53\%) in the cilengitide arm versus 115 patients $(45 \%)$ in the control arm. In the cilengitide arm, 11 patients (4\%) experienced TEAEs leading to death compared with 9 patients (3\%) in the control arm. Three patient deaths (1\%) in each study arm were considered treatment related (Supplementary Table 3). In the cilengitide arm, two patients (1\%) died of pulmonary embolism, and one $(<1 \%)$ of aspiration pneumonia; none of these patients had myelosuppression. In 
the control arm, one $(<1 \%)$ patient died of pancytopaenia and pneumonia, one $(<1 \%)$ of pneumonia after restarting TMZ following pancytopaenia, and one $(<1 \%)$ of septic shock without myelosuppression. Pneumocystis infections were not observed. 


\section{Discussion}

This large, prospective, phase 3 trial investigating the novel and first-in-class integrin inhibitor cilengitide as antitumour therapy in combination with standard chemoradiotherapy failed to demonstrate improved outcome. Neither PFS nor overall survival were significantly prolonged, and a HR of 1.02 for overall survival suggests absence of any activity. The median overall survival of $26 \cdot 3$ months observed in both treatment arms is consistent with prior reports and experience in this MGMT-methylated glioblastoma patient population who have undergone gross total or partial tumour resection. Safety and tolerability of cilengitide in combination with standard treatment were confirmed in this large multicentre trial; there was no indication of increased treatment-emergent toxicity with the addition of cilengitide.

These results raise the question of why the antitumour activity of cilengitide observed in prior phase 2 studies was not seen in this trial. Indeed, the extensive phase 1 and phase 2 clinical development programme repeatedly demonstrated objective and durable responses in patients with recurrent glioblastoma, ${ }^{18,19}$ provided evidence for the drug reaching the tumour tissue ${ }^{22}$ and indicated a dosedependent trend for a potential improved overall survival when comparing a higher and lower cilengitide dose in randomised trials for recurrent and newly diagnosed glioblastoma patients. ${ }^{19,21} \mathrm{At}$ the same time, cilengitide early development trials used either a lower dose $(500 \mathrm{mg}$ ) or compared different dosing regimens (500 vs 2000 mg cilengitide), but were conducted without standard of care controls, and their comparisons were based on historical data, ${ }^{18-21}$ which is in contrast to CENTRIC, where a control arm was included for comparison.

Cilengitide may induce some normalisation of the blood-brain barrier by itself, thus suggesting treatment response on imaging. Considering the short serum half-life of cilengitide of about 2-4 hours, ${ }^{18-20,28}$ a schedule of continuous i.v. administration rather than a twice-weekly bolus may have been more appropriate. Although low concentrations of cilengitide have been linked to proangiogenic activity in experimental tumour models and altered $\alpha v \beta 3$ integrin and vascular 
endothelial growth factor receptor-2 trafficking, ${ }^{29}$ we have previously argued that these experimental conditions probably do not reflect the clinical scenario of administering 2000 $\mathrm{mg} / \mathrm{m}^{2}$ cilengitide. ${ }^{30}$ This would be consistent with the observation that the cilengitide arm was comparable to the control arms in terms of safety, and no detrimental effect was observed in any subgroup analysed in the CENTRIC trial. Functional imaging demonstrating successful tumour targeting may also have been helpful. ${ }^{31}$

Numerous other agents were explored over the last decade in order to improve outcome of glioblastoma patients. Inhibition of angiogenesis remains a prime treatment target. Similarly to cilengitide, randomised trials of bevacizumab added to standard TMZ/RT in newly diagnosed glioblastoma failed to prolong overall survival, although PFS was prolonged. ${ }^{32,33}$ These repeatedly failed efforts underscore the complexity of this tumour type, and warrant better preclinical models and investigation of combined target inhibition and improved collaboration. More extensive and ideally controlled early phase clinical trials are needed, and a critical appraisal of the results required before moving into definitive large-scale phase 3 evaluations. Despite the negative outcome of the here reported trial, targeting integrins remains a theoretically attractive target, as they are involved in essential aspects of malignancy such as angiogenesis, migration, and invasion and their patterns in malignancies differ from those of their parent tissues, potentially allowing selective targeting. ${ }^{16}$

In the CENTRIC trial almost 3500 patients with a rare disease ${ }^{1}$ were screened and molecularly assessed for eligibility over a 2-year period. This underscores the urgent need for novel and better treatments for patients suffering from glioblastoma, and shows a substantial number of patients are affected by a disease often excluded from clinical drug development programmes. Potentially detrimental treatment delays have been a concern when seeking to molecularly characterise tumour types before allocation to specific treatments. In our trial the median time to treatment start was 56 weeks, well within the accepted range of up to 7 weeks. ${ }^{2}$ Similarly, the recently reported AVAglio study indicated that $96 \%$ of all patients started treatment within $4-7$ weeks $^{32}$ and in a trial evaluating treatments for elderly patients the median time to start of RT was $40-46$ days. ${ }^{26}$ Other publications 
do not report the time interval between surgery and treatment start. ${ }^{33}$ In our trial there was no indication that the time interval between initial diagnosis and treatment start influenced outcome.

A notable aspect of this trial was the unique collaboration of industry and academia. The trial was designed by academic teams of the EORTC and the Canadian Brain Tumor Consortium, in close collaboration with the manufacturer of cilengitide, Merck KGaA, Darmstadt, Germany. As this trial was designed as a registration trial of an entirely novel compound and a companion diagnostic, study sponsorship and management was coordinated by Merck KGaA, but investigators and representatives of the EORTC held the majority positions in the Steering Committee and were intimately involved in the study conduct and data interpretation. Data of all randomised patients were reviewed by the principal investigators, and statistical analyses were performed independently by the study teams at Merck and EORTC. Moreover, this close collaboration now allows assured longterm follow-up and expanded analyses of molecular tumour characteristics by EORTC-based platforms. While Merck KGaA is not pursuing further development of this compound, it continues to support the collaboration.

This trial demonstrated the feasibility of performing upfront central histological review and molecular testing with no significant delay in an international multicentre setting. This is a prerequisite for further drug development towards personalised medicine. 


\section{Panel: Research in context}

\section{Systematic review}

We screened PubMed and abstracts presented at clinical oncology meetings for reports of clinical trials investigating novel agents for newly diagnosed glioblastoma. Apart from combined chemoradiotherapy, the current standard treatment of care, the review revealed that there are no established alternative treatment options available for these patients, although several targeted agents and angiogenesis inhibitors are being investigated. Cilengitide showed activity in early phase trials, and efficacy was believed best when combined with other active treatments. Patients with a methylated MGMT promoter were found to have a better outcome with current treatments, thus this trial molecularly preselected patients with $M G M T$ methylation status. In a joint development by academia led by EORTC and the manufacturer this randomised comparative phase 3 trial was designed and conducted

\section{Interpretation}

Despite the encouraging results from preclinical and prior phase 1 and 2 studies, the results from this randomised phase 3 trial failed to demonstrate any improvement in outcome of glioblastoma patients when cilengitide is added to the standard chemoradiotherapy. The failure of cilengitide to improve outcomes in newly diagnosed glioblastoma highlights the pitfalls of conducting phase 3 trials based on limited phase 2 data and represents a drawback for integrin inhibition as a novel approach to cancer therapy. Only little progress in the treatment of glioblastoma has been made over the last decade.

The impressive international participation in the screening of over 3000 patients in this trial underscores the need for better treatments. We demonstrated that upfront molecular analyses and patient population enrichment is feasible. Successful collaboration between academia and industry 
performing a large clinical trial jointly while allowing for independence of the partners, separate statistical analyses and long-term follow-up has been shown. 


\section{Acknowledgements}

The authors would like to thank patients for their trust and participation, and their family members for the provided support and care. The authors are grateful to the many dedicated investigators, nurses, data-managers and other collaborators at the participating sites. They want to thank Robert Janzer (deceased) who also performed the central pathology review. Furthermore, the authors want to thank the members of the independent data monitoring committee, Prof Jan C. Buckner, Prof Jean-Pierre Armand, Prof Sally Stenning, Prof Sebastian Harder, and Dr Werner Holtbrügge. Finally, the authors would like to acknowledge the excellent collaboration of the teams at Merck KGaA, Quintiles, MDxHealth, the Canadian Brain Tumor Consortium, and the EORTC.

Editorial and medical writing assistance was provided by Anna Hooijkaas, PhD, TRM Oncology, The Hague, The Netherlands, funded by Merck KGaA, Darmstadt, Germany.

\section{Individual contribution of each author}

RS*: Study oversight, study design, data collection, data review and interpretation, manuscript writing

MEH*: Oversight molecular testing, study design, data collection, data review and interpretation, manuscript writing

TG*: Study design, data collection, data analysis, data interpretation, manuscript writing

SE*: Radiation therapy oversight, study design, data collection, data interpretation, manuscript writing

JP*: Study design, data collection, data interpretation, manuscript writing

YKH*: Study design, data collection, data interpretation, manuscript writing

KDA: Pathology review, manuscript writing 
BL: Pathology review, manuscript writing

TP: Pathology review, manuscript writing

DG: Data collection and interpretation, patient recruitment, manuscript writing

JPS: Data collection, data interpretation, manuscript writing

WW*: Data collection, manuscript writing

RT: Data collection, manuscript writing

DHN: Data collection, manuscript writing

PH: Data collection, manuscript writing

AW: Data collection, manuscript writing

MJBT: Data collection and interpretation, manuscript writing

CCS: Data collection, manuscript writing

NR: Data collection, manuscript writing

LT: Data collection, manuscript writing

UH: Data collection, manuscript writing

TG: Data collection, manuscript writing

RDK: Data collection, manuscript writing

KA: Data collection, manuscript writing

CMcB: Data collection, manuscript writing

AAB: Data collection, manuscript writing

JCT: Data collection, manuscript writing

OS: Data collection, manuscript writing 
TW: Data collection, manuscript writing

CYK: Data collection, manuscript writing

LBN: Study design, data collection, data interpretation, manuscript writing

DAR*: Study design, data collection, data interpretation, manuscript writing

MJvdB*: Study design, data collection, manuscript writing

CH: Study design, data collection, data analysis, data interpretation, manuscript writing

AM: Medical and scientific study support, data collection, data interpretation, manuscript writing

MP*: Study oversight, study design, data collection, data review and interpretation, manuscript writing

MW*: Study oversight, study design, data collection, data review and interpretation, manuscript writing

*Indicates steering committee member.

\section{Conflicts of interest}

RS: expenses in relationship with study from Merck KGaA; advisory board for Roche, MSD/Merck \& Co; and Novartis.

MEH: service contract from Merck Serono; grant from MDxHealth; personal fees from MSD; advisory fees from Roche and MDxHealth.

SE: grant from Merck KGaA.

TP: travel grant, honoraria, and payment for reference pathology from Merck, Roche, and Antisense Pharma.

JPS: advisory board for Roche and Mundipharma; personal fees from Medac; grant for independent scientific project from Merck. 
WW: grants from Roche, MSD, Eli Lilly, Boehringer Ingelheim, and Apogenix; personal fees from Roche and MSD.

RT: personal fees from Merck KGaA.

DHN: research funding from Merck Serono, Eli Lilly, Oncosynergy, and Regulus.

AW: personal fees from Roche.

MJBT: personal fees from Hoffman La Roche.

UH: consultancy role for Roche, personal fees from Roche, Medac, Mundipharma, research funding from Roche, Medac.

TG: grant from Merck KGaA.

KA: personal fees from Quintiles Eastern Holding.

CMcB: personal fees from Roche.

JCT: personal fees from Merck Serono, Roche, and Medac; grants from the German Cancer Foundation (Krebshilfe), German Research Foundation (DFG), and the German Ministry of Research and Technology (BMBF).

OS: personal fees from Roche.

DAR: personal fees from Roche/Genentech, Merck/Schering, EMD Serono, Novartis, Amgen, Stemline Therapeutics, and Momenta Pharmaceuticals.

MJvdB: personal fees from Merck KGaA, Hoffman La Roche, AstraZeneca, Abbvie, and MSD; grants from Hoffman La Roche and Abbvie.

CH: employed by Merck KGaA; owner of stock from Merck KGaA.

AM, MP: employed by Merck KGaA. 
MW: consultant or advisory role for Isarna, Merck Serono, Roche, and Magforce; personal fees from Merck Serono, Roche, MSD, and Magforce; research funding from Bayer, Merck Serono, Roche, MSD, and Isarna.

JP, YKH, KDA, BL, DG, PH, CCS, NR, LT, RDK, AAB, TW, CYK, LBN: No conflicts of interest to disclose. 


\section{References}

1. Dolecek TA, Propp JM, Stroup NE, Kruchko C. CBTRUS statistical report: primary brain and central nervous system tumors diagnosed in the United States in 2005-2009. Neuro-Oncol 2012;14:v1-49.

2. Stupp R, Mason WP, van den Bent MJ, et al. Radiotherapy plus concomitant and adjuvant temozolomide for glioblastoma. N Engl J Med 2005;352:987-96.

3. Johnson DR, O'Neill BP. Glioblastoma survival in the United States before and during the temozolomide era. J Neurooncol 2012;107:359-64.

4. Gilbert MR, Wang M, Aldape KD, et al. Dose-dense temozolomide for newly diagnosed glioblastoma: a randomized phase III clinical trial. J Clin Oncol 2013;31:4085-91

5. Weller M, Van den Bent M, Hopkins K, et al., for the European Association for NeuroOncology (EANO) Task Force on Malignant Glioma. EANO Guideline on the Diagnosis and Treatment of Malignant Glioma. Lancet Oncol 2014; in press.

6. Agarwal S, Sane R, Oberoi R, Ohlfest JR, Elmquist WF. Delivery of molecularly targeted therapy to malignant glioma, a disease of the whole brain. Expert Rev Mol Med 2011;13:e17.

7. Haar $\mathrm{CP}$, Hebbar P, Wallace GC 4th, et al. Drug resistance in glioblastoma: a mini review. Neurochem Res 2012;37:1192-200.

8. Jaeckle KA, Eyre HJ, Townsend JJ, et al. Correlation of tumor 06 methylguanine-DNA methyltransferase levels with survival of malignant astrocytoma patients treated with bischloroethylnitrosourea: a Southwest Oncology Group study. J Clin Oncol 1998;16:3310-5.

9. Hegi ME, Diserens AC, Godard S, et al. Clinical trial substantiates the predictive value of O-6methylguanine-DNA methyltransferase promoter methylation in glioblastoma patients treated with temozolomide. Clin Cancer Res 2004;15:1871-4. 
10. Hegi ME, Diserens AC, Gorlia T, et al. MGMT gene silencing and benefit from temozolomide in glioblastoma. N Engl J Med 2005;352:997-1003.

11. Hoelzinger DB, Demuth T, Berens ME. Autocrine factors that sustain glioma invasion and paracrine biology in the brain microenvironment. J Natl Cancer Inst 2007;99:1583-93.

12. Stupack DG. The biology of integrins. Oncology (Williston Park) 2007;21:6-12.

13. Bello L, Francolini $M$, Marthyn $\mathrm{P}$, et al. Alpha(v)beta3 and alpha(v)beta5 integrin expression in glioma periphery. Neurosurgery 2001;49:380-9.

14. Schnell O, Krebs B, Wagner E, et al. Expression of integrin alphavbeta3 in gliomas correlates with tumor grade and is not restricted to tumor vasculature. Brain Pathol 2008;18:378-86.

15. Roth $\mathrm{P}$, Silginer $\mathrm{M}$, Goodman $\mathrm{SL}$, et al. Integrin control of the transforming growth factor- $\beta$ pathway in glioblastoma. Brain 2013;136:564-76.

16. Desgrosellier JS, Cheresh DA. Integrins in cancer: biological implications and therapeutic opportunities. Nat Rev Cancer 2010;10:9-22.

17. Smith JW. Cilengitide Merck. Curr Opin Investig Drugs 2003;4:741-5.

18. Nabors LB, Mikkelsen T, Rosenfeld SS, et al. Phase I and correlative biology study of cilengitide in patients with recurrent malignant glioma. J Clin Oncol 2007;25:1651-7.

19. Reardon DA, Fink KL, Mikkelsen T, et al. Randomized phase II study of cilengitide, an integrintargeting arginine-glycine-aspartic acid peptide, in recurrent glioblastoma multiforme. J Clin Oncol 2008;26:5610-7.

20. Stupp R, Hegi ME, Neyns B, et al. Phase I/lla study of cilengitide and temozolomide with concomitant radiotherapy followed by cilengitide and temozolomide maintenance therapy in patients with newly diagnosed glioblastoma. J Clin Oncol 2010;28:2712-8. 
21. Nabors LB, Mikkelsen T, Hegi ME, et al. A safety run-in and randomized phase 2 study of cilengitide combined with chemoradiation for newly diagnosed glioblastoma (NABTT 0306). Cancer 2012;118:5601-7.

22. Gilbert MR, Kuhn J, Lamborn KR, et al. Cilengitide in patients with recurrent glioblastoma: the results of NABTC 03-02, a phase II trial with measures of treatment delivery. I Neurooncol 2012;106:147-53.

23. Mikkelsen T, Brodie C, Finniss S et al. Radiation sensitization of glioblastoma by cilengitide has unanticipated schedule-dependency. Int J Cancer 2009;124:2719-27.

24. Nabors LB, Fink KL, Mikkelsen T, et al. Cilengitide in combination with standard treatment for patients with newly diagnosed glioblastoma with unmethylated 06-methylguanine-DNA methyltransferase (MGMT) gene promoter: key results of the open-label, controlled, randomized phase II CORE study. Neurooncol 2013;15:viii75-84. Abstract MR-021.

25. Vlassenbroeck I, Califice S, Diserens AC, et al. Validation of real-time methylation-specific PCR to determine 06-methylguanine-DNA methyltransferase gene promoter methylation in glioma. J Mol Diagn 2008;10:332-7.

26. Malmström A, Grønberg BH, Marosi C, et al. Temozolomide versus standard 6-week radiotherapy versus hypofractionated radiotherapy in patients older than 60 years with glioblastoma: the Nordic randomised, phase 3 trial. Lancet Oncol 2012;9:916-26.

27. Wen YP, Macdonald DR, Reardon DA, et al. Updated Response Assessment Criteria for HighGrade Gliomas: Response Assessment in Neuro-Oncology Working Group. J Clin Oncol 2010;28:1963-72.

28. Hariharan S, Gustafson D, Holden S, et al. Assessment of the biological and pharmacological effects of the alpha nu beta3 and alpha nu beta5 integrin receptor antagonist, cilengitide (EMD 121974), in patients with advanced solid tumors. Ann Oncol 2007;18:1400-7. 
29. Reynolds AR, Hart IR, Watson AR, et al. Stimulation of tumor growth and angiogenesis by low concentrations of RGD-mimetic integrin inhibitors. Nat Med 2009;15:392-400.

30. Weller M, Reardon D, Nabors B, et al. Will integrin inhibitors have proangiogenic effects in the clinic? Nat Med. 2009;15:726; author reply 727.

31. Schnell O, Krebs B, Carlsen J, et al. Imaging of integrin alpha(v)beta(3) expression in patients with malignant glioma by [18F] Galacto-RGD positron emission tomography. Neuro Oncol 2009;11:861-70.

32. Chinot OL, Wick W, Mason W, et al. Bevacizumab plus radiotherapy-temozolomide for newly diagnosed glioblastoma. N Engl J Med 2014;370:709-22.

33. Gilbert MR, Dignam JJ, Armstrong TS, et al. A randomized trial of bevacizumab for newly diagnosed glioblastoma. N Engl J Med.2014;370(8):699-708. 
Tables

Table 1. Patient baseline characteristics and demographics (ITT population)

\begin{tabular}{|c|c|c|}
\hline & $\begin{array}{l}\text { Cilengitide arm } \\
\qquad(n=272)\end{array}$ & $\begin{array}{c}\text { Control arm } \\
(n=273)\end{array}$ \\
\hline \multicolumn{3}{|l|}{ Age (years) } \\
\hline Median (range) & $58(22-81)$ & $58(22-79)$ \\
\hline \multicolumn{3}{|l|}{ Sex, n (\%) } \\
\hline Male & $148(54)$ & $143(52)$ \\
\hline \multicolumn{3}{|l|}{ Region, n (\%) } \\
\hline North America & $32(12)$ & $33(12)$ \\
\hline Europe & $185(68)$ & $183(67)$ \\
\hline Rest of the World & $55(20)$ & $57(21)$ \\
\hline \multicolumn{3}{|c|}{ ECOG performance status, $n(\%)$} \\
\hline 0 & $156(57)$ & $151(55)$ \\
\hline$\geq 1$ & $116(43)$ & $121(44)$ \\
\hline Missing & $0(0)$ & $1(<1)$ \\
\hline \multicolumn{3}{|l|}{ RPA class, n (\%) } \\
\hline III & $44(16)$ & $42(15)$ \\
\hline IV & $184(68)$ & $171(63)$ \\
\hline $\mathrm{V}$ & $43(16)$ & $55(20)$ \\
\hline Missing & $1(<1)$ & $5(2)$ \\
\hline \multicolumn{3}{|l|}{ MMSE, n (\%) } \\
\hline$<27$ & $45(17)$ & $61(22)$ \\
\hline$\geq 27$ & $225(83)$ & $207(76)$ \\
\hline Missing & $2(<1)$ & $5(2)$ \\
\hline
\end{tabular}

Extent of resection, $n$ (\%)

Gross total resection

$132(49)$

$137(50)$ 


\begin{tabular}{lcc} 
Partial resection & $131(48)$ & $127(47)$ \\
Biopsy & $9(3)$ & $7(3)$ \\
Missing & $0(0)$ & $2(1)$ \\
\hline Antiepileptics (baseline), $\mathbf{n}(\%)$ & & $57(21)$ \\
EIAED & $54(20)$ & $121(44)$ \\
Non-EIAED only & $99(36)$ & $94(34)$ \\
None & $119(44)$ & $113(41)$ \\
\hline Steroids (baseline), $\mathbf{n}(\%)$ & $103(38)$ & \\
Yes & & \\
\hline Time from diagnosis to \\
randomisation (weeks) \\
$\begin{array}{l}\text { Median (range) } \\
\text { Time from diagnosis to } \\
\text { start of RT (weeks) } \\
\text { Median (range) }\end{array}$ \\
\hline
\end{tabular}

ITT, intention-to-treat; ECOG, Eastern Cooperative Oncology Group; RPA, recursive partitioning analysis; MMSE, Mini-Mental State Examination; EIAED, enzyme-inducing antiepileptic drugs; RT, radiotherapy. 
Table 2. Most common TEAEs by preferred term (safety population; any grade observed in at least $10 \%$ of patients or grade $\geq 3$ reported in at least $2 \%$ of patients)*

\begin{tabular}{|c|c|c|c|c|c|c|}
\hline \multirow[b]{2}{*}{ Preferred term, n (\%) } & \multicolumn{3}{|c|}{ Cilengitide arm ( $n=263)$} & \multicolumn{3}{|c|}{ Control arm $(n=258)$} \\
\hline & $\begin{array}{l}\text { Any } \\
\text { grade }\end{array}$ & Grade 3 & Grade 4 & $\begin{array}{l}\text { Any } \\
\text { grade }\end{array}$ & Grade 3 & Grade 4 \\
\hline Nausea & $130(49)$ & $3(1)$ & - & $127(49)$ & $5(2)$ & - \\
\hline Headache & $119(45)$ & $10(4)$ & - & $88(34)$ & $8(3)$ & - \\
\hline Fatigue & $102(39)$ & $14(5)$ & - & $85(33)$ & $8(3)$ & - \\
\hline Constipation & $102(39)$ & $2(1)$ & - & $78(30)$ & - & - \\
\hline Vomiting & $80(30)$ & $3(1)$ & - & $87(34)$ & $9(3)$ & - \\
\hline Alopecia & $70(27)$ & $2(1)$ & - & $70(27)$ & $1(<1)$ & - \\
\hline Thrombocytopaenia & $62(24)$ & $15(6)$ & $13(5)$ & $70(27)$ & $20(8)$ & $26(10)$ \\
\hline Convulsion & $57(22)$ & $9(3)$ & $5(2)$ & $28(11)$ & $13(5)$ & $2(1)$ \\
\hline Decreased appetite & $54(21)$ & $1(<1)$ & - & $45(17)$ & - & - \\
\hline Cough & $51(19)$ & $1(<1)$ & - & $23(9)$ & - & - \\
\hline Asthaenia & $47(18)$ & $8(3)$ & - & $21(8)$ & $3(1)$ & - \\
\hline Lymphopaenia & $46(17)$ & $24(9)$ & $7(3)$ & $36(14)$ & $24(9)$ & $2(1)$ \\
\hline Diarrhoea & $45(17)$ & $3(1)$ & - & $20(8)$ & $2(1)$ & - \\
\hline Dizziness & $36(14)$ & $2(1)$ & - & $25(10)$ & $1(<1)$ & - \\
\hline Oedema peripheral & $36(14)$ & $2(1)$ & - & $24(9)$ & $1(<1)$ & - \\
\hline Neutropaenia & $35(13)$ & $10(4)$ & $9(3)$ & $29(11)$ & $11(4)$ & $13(5)$ \\
\hline Insomnia & $35(13)$ & - & - & 24 (9) & - & - \\
\hline Leukopaenia & $33(13)$ & $13(5)$ & $5(2)$ & $33(13)$ & $11(4)$ & $9(3)$ \\
\hline Nasopharyngitis & $32(12)$ & - & - & $11(4)$ & - & - \\
\hline Pruritus & $32(12)$ & $2(1)$ & - & $15(6)$ & - & - \\
\hline Back pain & $31(12)$ & $1(<1)$ & - & $8(3)$ & $2(1)$ & - \\
\hline Pyrexia & $30(11)$ & $2(1)$ & - & $19(7)$ & - & - \\
\hline Rash & $28(11)$ & $1(<1)$ & - & $19(7)$ & $1(<1)$ & - \\
\hline $\begin{array}{l}\text { Upper respiratory tract } \\
\text { infection }\end{array}$ & $28(11)$ & - & - & $16(6)$ & - & - \\
\hline
\end{tabular}




\begin{tabular}{lcccccc} 
Memory impairment & $27(10)$ & $1(<1)$ & - & $18(7)$ & $1(<1)$ & - \\
Aphasia & $25(10)$ & $6(2)$ & - & $12(5)$ & $5(2)$ & - \\
Haemiparesis & $21(8)$ & $11(4)$ & $1(<1)$ & $11(4)$ & $4(2)$ & $1(<1)$ \\
Alanine & $21(8)$ & $7(3)$ & - & $17(7)$ & $4(2)$ & - \\
aminotransferase & & & & & & \\
Aneamia & $17(6)$ & $7(3)$ & - & $17(7)$ & $2(1)$ & $2(1)$ \\
$\begin{array}{l}\text { Pneumonia } \\
\text { Peripheral motor }\end{array}$ & $15(6)$ & $9(3)$ & $2(1)$ & $11(4)$ & $3(1)$ & $3(1)$ \\
neuropathy & $9(3)$ & - & $3(1)$ & $1(<1)$ & - \\
Hyperglycaemia & $13(5)$ & $11(4)$ & - & $8(3)$ & $5(2)$ & - \\
$\begin{array}{l}\text { Deep vein thrombosis } \\
\text { Lymphocyte count }\end{array}$ & $13(5)$ & $10(4)$ & - & $6(2)$ & $4(2)$ & $2(1)$ \\
decreased & $13(5)$ & $7(3)$ & $3(1)$ & $6(2)$ & $1(<1)$ & $1(<1)$ \\
$\begin{array}{l}\text { Pulmonary embolism } \\
\text { Hyponatraemia }\end{array}$ & $13(5)$ & $2(1)$ & $10(4)$ & $8(3)$ & $1(<1)$ & $6(2)$ \\
White blood cell count & $14(5)$ & $4(2)$ & $2(1)$ & $8(3)$ & $7(3)$ & - \\
\hline
\end{tabular}

*If a patient experienced more than $1 \mathrm{AE}$ within a preferred term, the patient was counted once in the term.

In this study, grade 5 was not possible to assign to an AE; those AEs were recorded as grade 3 or 4 leading to death (Supplementary Table 3).

$A E$, adverse events; TEAE, treatment-emergent adverse event. 


\section{Figures}

Figure 1. Treatment scheme.

\begin{tabular}{|c|c|}
\hline Step 1: & Step 2: \\
Central pathology review and & Randomisation \\
MGMT methylation status assay & \\
\hline
\end{tabular}

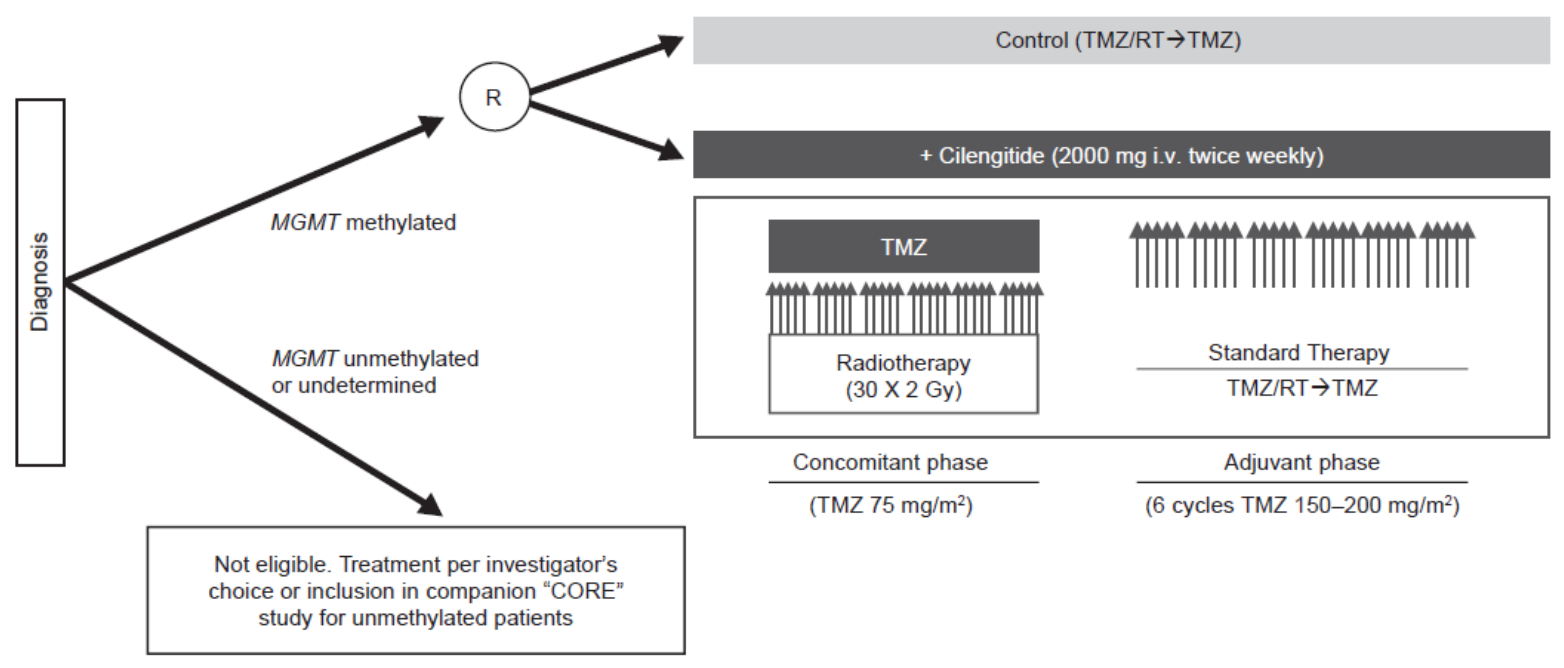

$M G M T, O^{6}$-methylguanine-DNA methyltransferase; $\mathrm{R}$, randomisation; i.v., intravenous; $\mathrm{TMZ}$, temozolomide; RT, radiotherapy; Gy, Gray. 
Figure 2. CONSORT statement diagram.

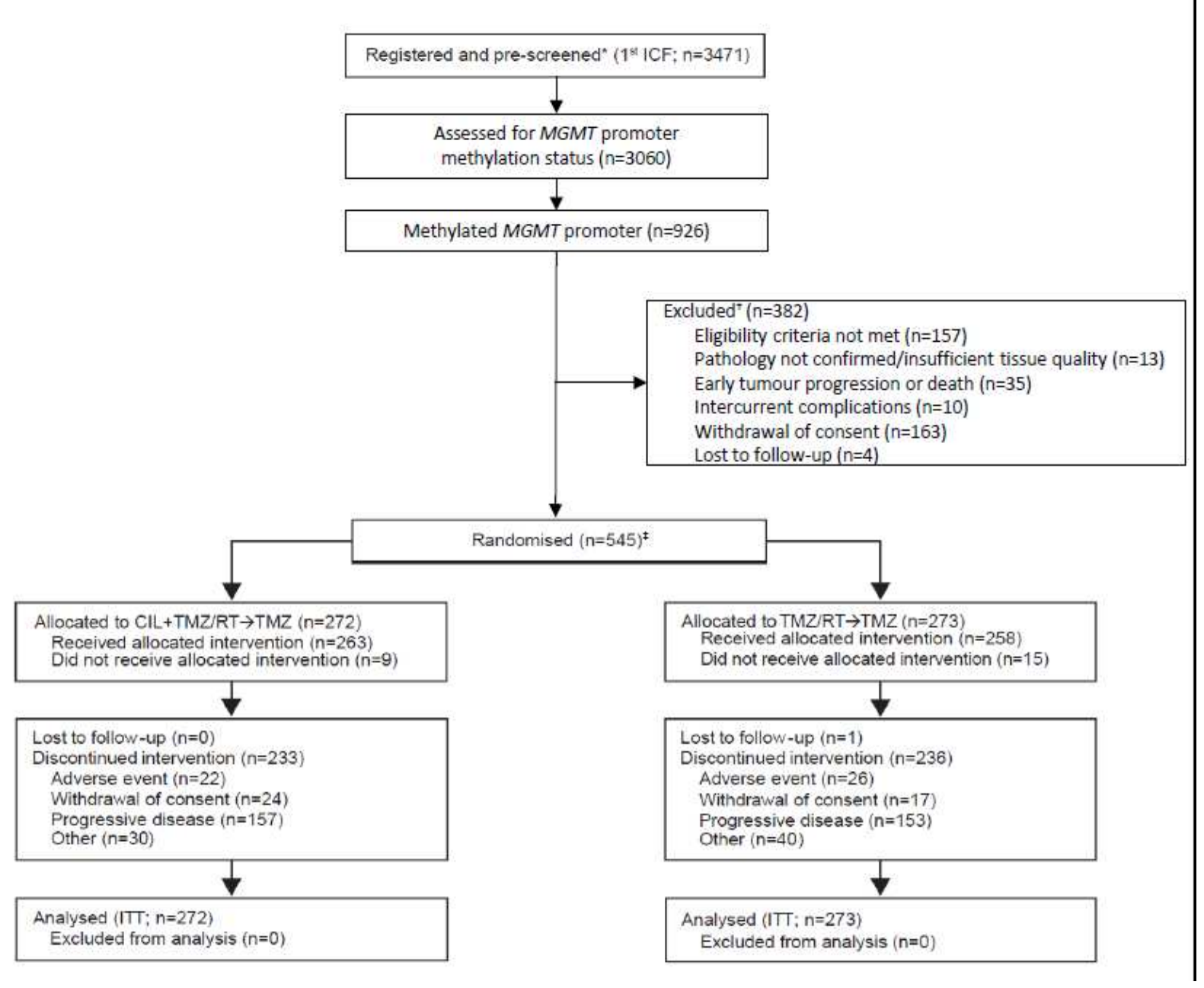

"Pre-screening for methylation status of the MGMT gene promoter.

${ }^{\dagger}$ Reasons for exclusion as reported by the investigator.

${ }^{\ddagger} 1$ patient with unmethylated MGMT gene promoter was randomised erroneously.

$M G M T, O^{6}$-methylguanine-DNA methyltransferase; ICF, informed consent form; ITT, intention-totreat; $\mathrm{TMZ}$, temozolomide; $\mathrm{RT}$, radiotherapy; $\mathrm{ClL}$, cilengitide. 
Figure 3. Kaplan-Meier plot of OS (A) and forest plot (B) detailing OS based on patient demographics (ITT population).

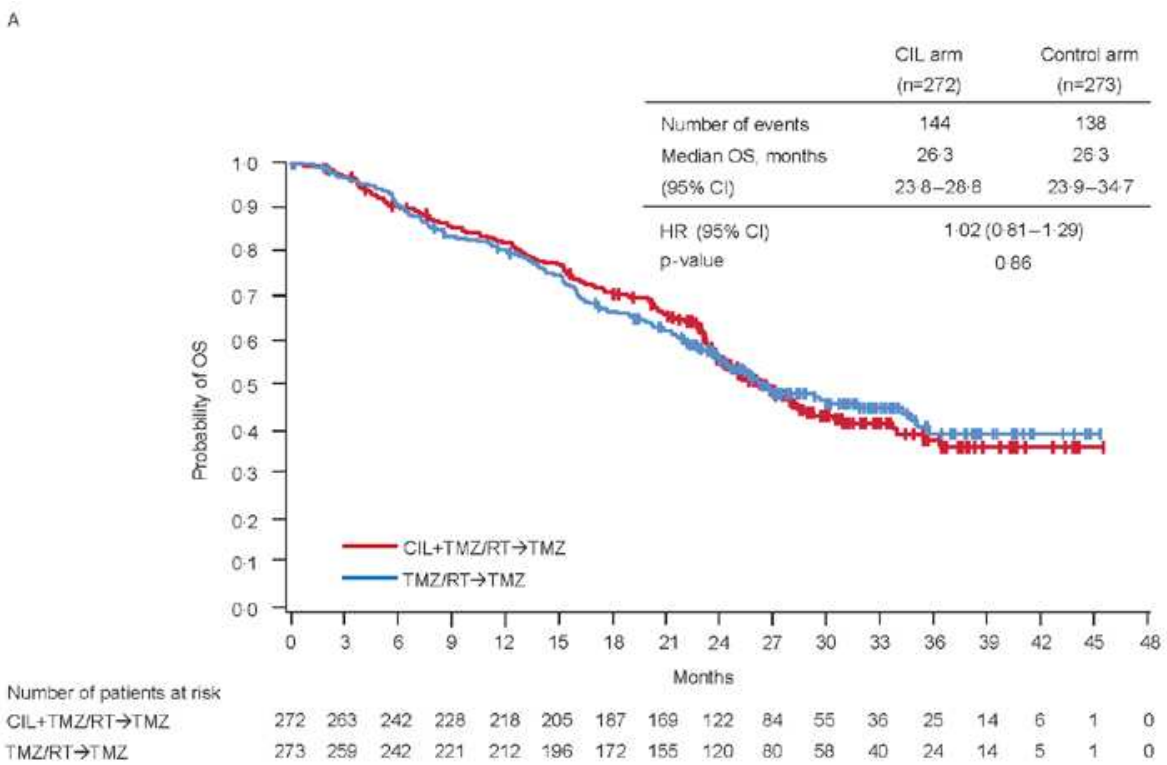

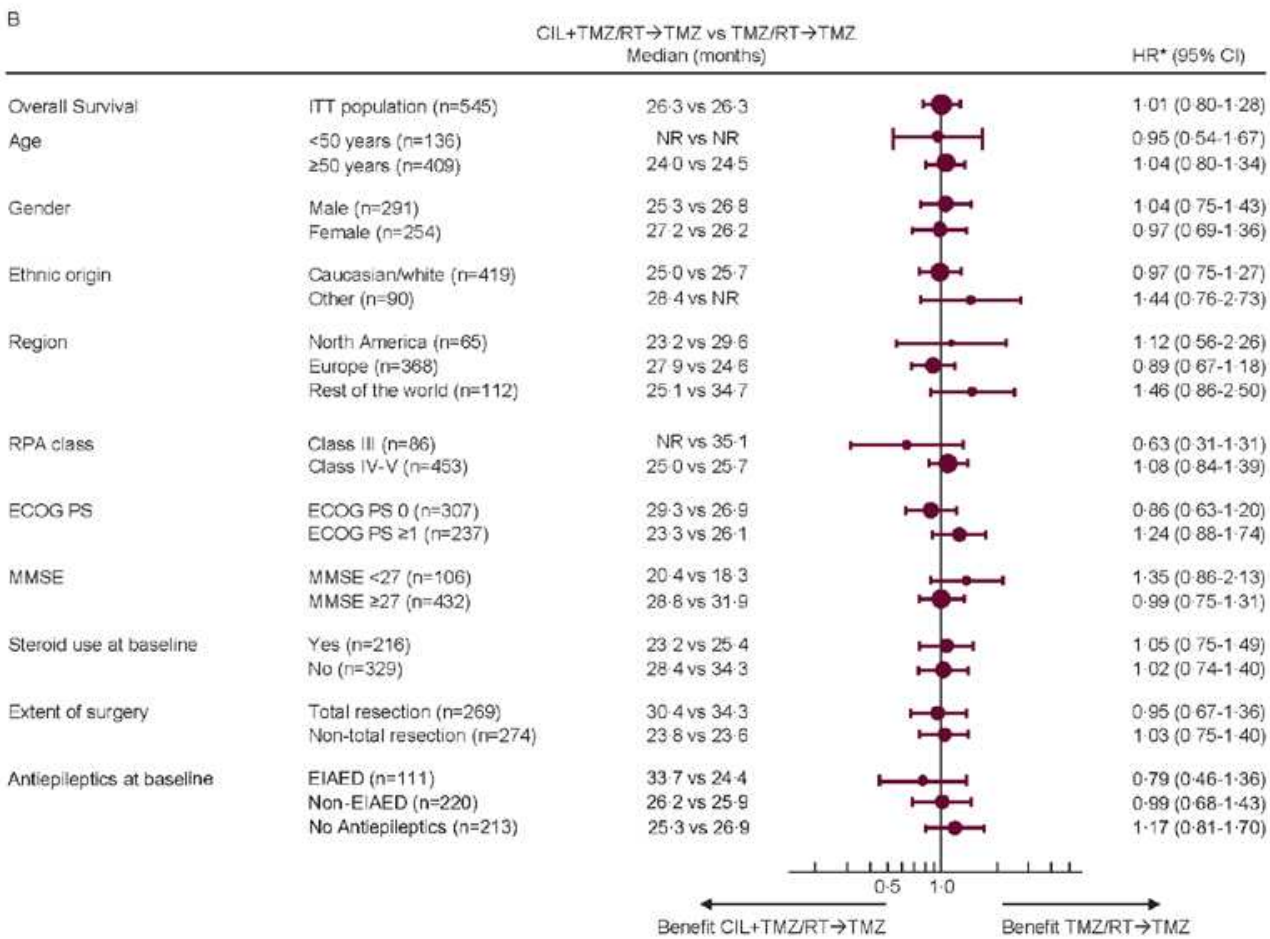

*Stratified HR is displayed in all Kaplan Meier analyses; unstratified HRs are displayed in all subgroup analyses.

$\mathrm{HR}$, hazard ratio; $\mathrm{Cl}$, confidence interval; OS, overall survival; TMZ, temozolomide; $\mathrm{RT}$, radiotherapy; $\mathrm{CIL}$, cilengitide; MGMT, $O^{6}$-methylguanine-DNA methyltransferase; NR, median not yet reached; RPA, 
recursive partitioning analysis; ITT, intention-to-treat; ECOG PS, Eastern Cooperative Oncology Group performance status; MMSE, Mini Mental State Examination; EIAED, enzyme-inducing antiepileptic drugs. 
Figure 4. PFS as assessed by the investigator (A) and assessed by the IRC (B) (ITT population).

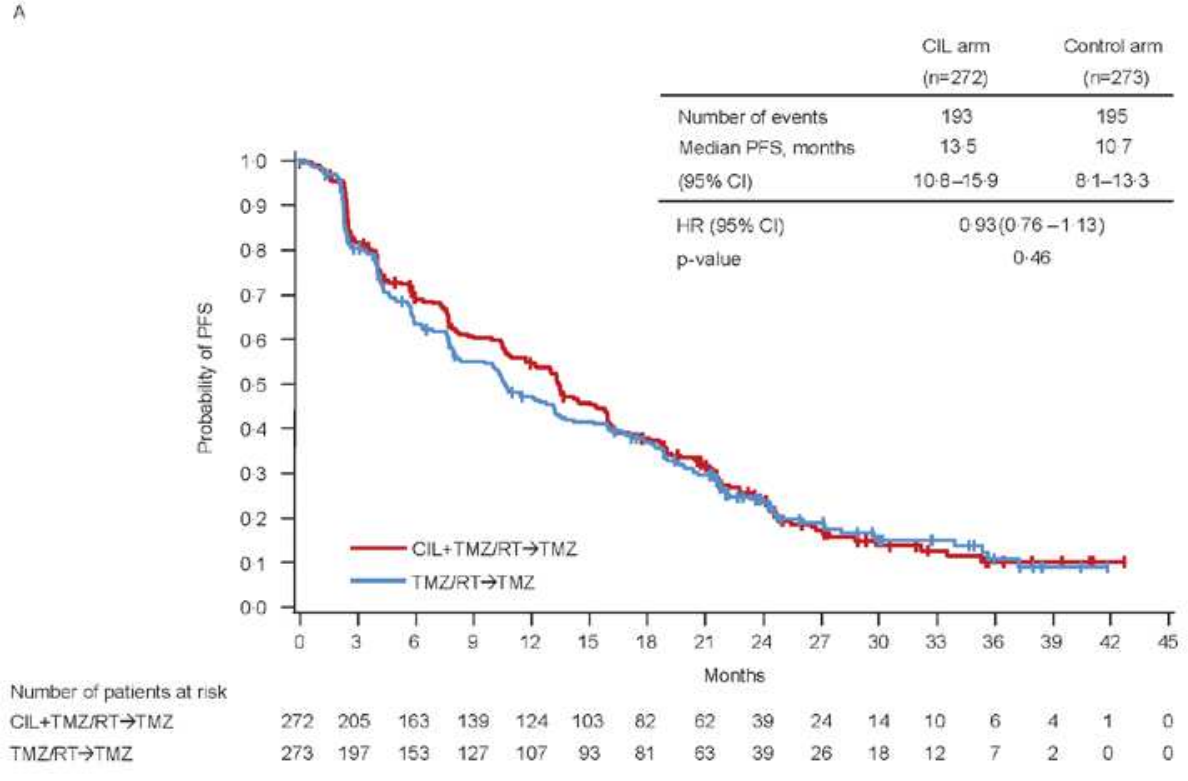

B

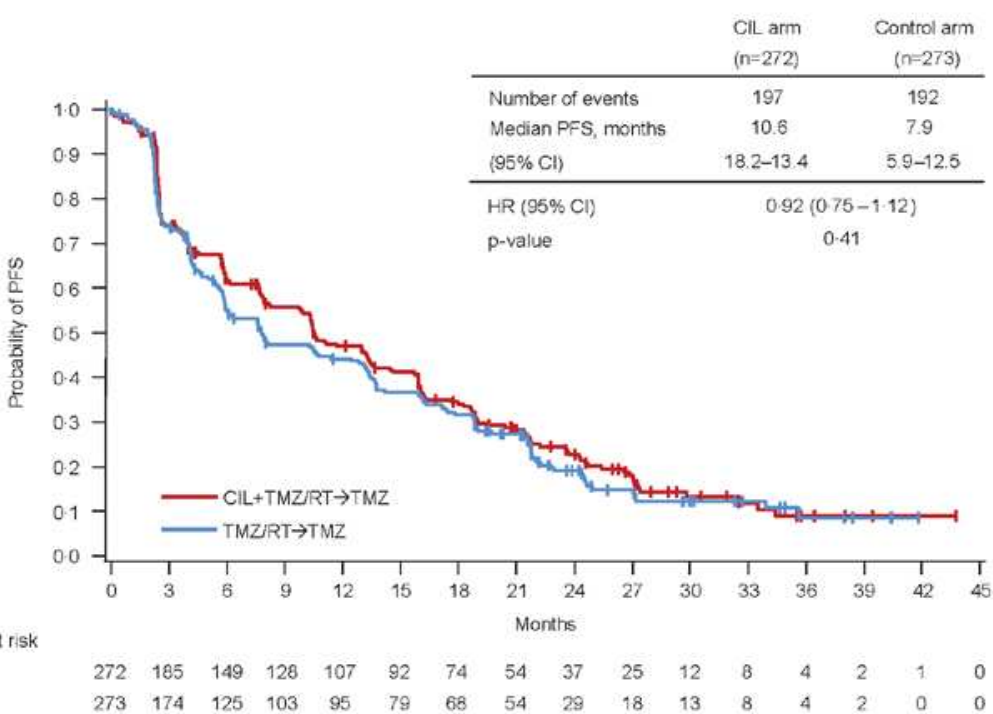

$\mathrm{CIL}$, cilengitide; $\mathrm{Cl}$, confidence interval; HR, hazard ratio; ITT, intention-to-treat; PFS, progression-free survival; TMZ, temozolomide; $\mathrm{RT}$, radiotherapy. 


\section{Figure 2}

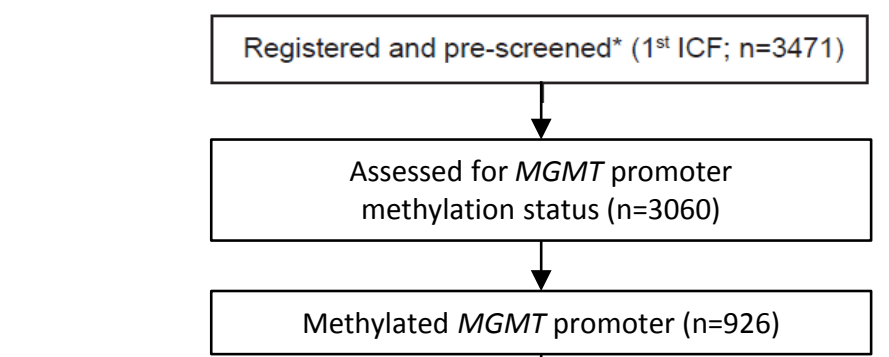

Allocated to $\mathrm{ClL}+\mathrm{TMZ} / \mathrm{RT} \rightarrow \mathrm{TMZ}(\mathrm{n}=272)$

Received allocated intervention $(n=263)$

Did not receive allocated intervention $(n=9)$

Lost to follow-up $(n=0)$

Discontinued intervention $(n=233)$

Adverse event $(n=22)$

Withdrawal of consent $(n=24)$

Progressive disease $(n=157)$

Other $(n=30)$

Analysed (ITT; $\mathrm{n}=272$ )

Excluded from analysis $(n=0)$
Excluded $^{\dagger}(n=382)$

Eligibility criteria not met $(n=157)$

Pathology not confirmed/insufficient tissue quality $(n=13)$

Early tumour progression or death $(n=35)$

Intercurrent complications $(n=10)$

Withdrawal of consent $(n=163)$

Lost to follow-up (n=4) 


\section{Supplementary materials}

Supplementary Table 1. Treatment following documented PD (ITT population)

\begin{tabular}{lcc}
\hline & $\begin{array}{c}\text { Cilengitide arm } \\
(\mathbf{n = 2 7 2})\end{array}$ & $\begin{array}{c}\text { Control arm } \\
(\mathbf{n = 2 7 3})\end{array}$ \\
\hline Patients with documented PD, n (\%) & $157(58)$ & $153(56)$ \\
Treatment following documented PD, n (\%) & $151(55)$ \\
$\geq 1$ Therapy & $152(56)$ & $25(9)$ \\
Surgery & $32(12)$ & $40(15)$ \\
Radiotherapy & $26(10)$ & $105(39)$ \\
Cytotoxic chemotherapy & $113(42)$ & $0(0)$ \\
Hormonal & $1(<1)$ & $27(10)$ \\
Anti-VEGF (other than bevacizumab) & $29(11)$ & $54(20)$ \\
Bevacizumab & $52(19)$ & $25(9)$ \\
Other antiangiogenic & $24(9)$ & $21(8)$ \\
Other & $19(7)$ & \\
\hline
\end{tabular}

ITT, intention-to-treat; PD, progressive disease; VEGF, vascular endothelial growth factor. 
Supplementary Table 2. Patients with TEAEs (safety population)

\begin{tabular}{lcc}
\hline & $\begin{array}{c}\text { Cilengitide arm } \\
(\mathbf{n = 2 6 3})\end{array}$ & $\begin{array}{c}\text { Control arm } \\
(\mathbf{n = 2 5 8}) \\
\mathbf{n}(\mathbf{\%})\end{array}$ \\
\hline TEAEs & $261(99)$ & $253(98)$ \\
Any & $229(87)$ & $222(86)$ \\
Study treatment related & $132(50)$ & $N A$ \\
Considered as cilengitide related & & \\
Serious AEs & & $115(45)$ \\
Any & $138(53)$ & $47(18)$ \\
Study treatment related & $55(21)$ & $N A$ \\
Considered as cilengitide related & $30(11)$ & $158(61)$ \\
NCI-CTCAE grade 3 or 4 TEAEs & & $101(39)$ \\
Any & $169(64)$ & $N A$ \\
Study treatment related & $100(38)$ & $9(4)$ \\
Considered as cilengitide related & $52(20)$ & $3(1)$ \\
TEAEs leading to death & & $N A$ \\
Any & $11(4)$ & $37(14)$ \\
Study treatment related & $3(1)$ & $N A$ \\
Considered as cilengitide related & $2(1)$ & $19(7)$ \\
TEAEs leading to permanent discontinuation of & & $N A$ \\
At least 1 study treatment & $60(23)$ & \\
Cilengitide & $43(16)$ & \\
TEAEs leading to dose reduction of & & \\
At least 1 study treatment & $27(10)$ & \\
Cilengitide & $12(5)$ & \\
\hline
\end{tabular}

*A serious AE, experience, or reaction is any untoward medical occurrence that at any dose results in death or is life-threatening (ie, refers to an event in which the patient was at risk of death at the time of the event).

Study treatment-related: cilengitide, radiotherapy, and/or temozolomide.

AE, adverse event; NA, not applicable; NCI-CTCAE, National Cancer Institute Common Terminology Criteria for AEs; TEAE, treatment-emergent AE. 
Supplementary Table 3. Study treatment-related AEs leading to death by SOC/preferred term (safety population)*

\begin{tabular}{lcc}
\hline & $\begin{array}{c}\text { Cilengitide arm } \\
(\mathbf{n = 2 6 3}) \\
\mathbf{n}(\boldsymbol{\%})\end{array}$ & $\begin{array}{c}\text { Control arm } \\
(\mathbf{n = 2 5 8}) \\
\mathbf{n}(\boldsymbol{\%})\end{array}$ \\
\hline Number of patients with $\geq \mathbf{1} \mathbf{A E}$ & $3(1)$ & $3(1)$ \\
Blood and lymphatic system disorders & 0 & $1(<1)$ \\
Leukopaenia & 0 & $1(<1)$ \\
Lymphopaenia & 0 & $1(<1)$ \\
Neutropaenia & 0 & $1(<1)$ \\
Thrombocytopaenia & 0 & $1(<1)$ \\
Infections and infestations & 0 & $3(1)$ \\
Pneumonia & 0 & $2(1)$ \\
Septic shock & 0 & $1(<1)$ \\
Respiratory, thoracic, and mediastinal disorders & $3(1)$ & 0 \\
Pneumonia aspiration & $1(<1)$ & 0 \\
Pulmonary embolism & $2(1)$ & 0 \\
\hline
\end{tabular}

*If a patient experienced $\geq 1 \mathrm{AE}$ within a SOC/preferred term, the patient was counted once in that SOC/preferred term.

Study treatment-related: cilengitide, radiotherapy, or temozolomide.

AE, adverse event; SOC, System Organ Class. 


\section{Appendix - list of participating institutions}

Argentina: Fundación para la Lucha contra las Enfermedades Neurológicas de la Infancia - FLENI (B. Diez), Instituto Médico CER (M.S. Varela), Sanatorio Parque (S. Kahl)

Australia: Haematology \& Oncology Clinics of Australia - HOCA (P. Eliadis), Royal Melbourne Hospital (M. Rosenthal), Austin Health (L. Cher), The Queen Elizabeth Hospital (K. Patterson), Royal North Shore Hospital (H. Wheeler), Calvary Mater Newcastle Hospital (S. Ackland), Royal Brisbane \& Women's Hospital (J. Goh), Flinders Medical Centre (G. Kichenadasse)

Austria: Universitätsklinik für Innere Medizin I (C. Marosi), Universitätsklinik Graz (F. Payer), St. Johanns Spital - Landeskrankenhaus (R. Greil), Universitätsklinik Innsbruck (G. Stockhammer), Kaiser-Franz-Josef Spital (W. Grisold)

Belgium: UZ Brussel (B. Neyns), U.Z. Gasthuisberg (P. Clement), ZNA Middelheim (D. Schrijvers), Grand Hôpital Charleroi (J.L. Canon), Onze-Lieve-Vrouwziekenhuis (L. Verbeke), ZOL (J. Wuyts), UZ Gent (T. Boterberg), Cliniques universitaires UCL de Mont-Godinne (L. D'Hondt)

Brazil: Hospital Sao Lucas - PUCRS (F. Viola), HC da Faculdade de Medicina de Ribeirão Preto da USP (F. Maris Peria), IAMSPE (J.M. Rotta), Nucleo de Estudos Oncológicos (M.d. S. Oliveira), Hospital do Cancer Instituto do Cancer do Ceara (M. Gifoni), CEPON (Y.V.N. Nascimento)

Canada: London Health Sciences Centre (D. MacDonald), Windsor Regional Cancer Centre (Y. Alam), Montreal Neurological Institute and Hospital McGill University (T. Muanza), Queen Elizabeth II Health Sciences Centre (M. MacNeil), Tom Baker Cancer Centre (G. Lim), CancerCare Manitoba (M. Pitz), Sunnybrook Health Sciences Centre (J. Perry), Cross Cancer Institute (D. Fulton), Hamilton Health SciencesJuravinski Cancer Centre (H. Hirte), CHUS Hopital Fleurimont (D. Mathieu)

Czech Republic: Klinika Onkologie a Radioterapie - Fakultni nemocnice Hradec Kralove (J. Petera), Oddeleni radiacni onkologie - Krajska nemocnice Liberec (M. Machanova), Ustav radiacni onkologie 1LF UK - Fakultni nemocnice Na Bulovce (V. Stahalova), Radioterapeuticko-Onkologicke oddeleni Fakultni nemocnice v Motole (J. Prausova), Klinika radiacni onkologie - Masarykuv onkologicky ustav (P. Slampa), Onkologicke a Radoterapeuticke - oddeleni Fakultni nemocnice Plzen (J. Finek)

France: CH Pitié-Salpétrière (J.Y. Delattre), CHU de la Timone (O. Chinot), Centre Val d'Aurelle Paul Lamarque (M. Fabbro), Centre René Gauducheau (M. Campone), Institut Gustave Roussy (J. Domont), CHU d'Angers (P. Menei), CLCC Paul Strauss (R. Schott), Hopital Neuro Cardiologique (J. Honnorat), CHRU Hopital Roger Salengro (F. Dubois), Institut Claudius Regaud (E. Moyal), Centre Antoine Lacassagne (M. Frenay), Hopital Pellegrin Tripode (H. Loiseau), Centre Léon Bérard (D. Frappaz), Hôpital Central - Service Neurologie (L. Taillandier), Centre Hospitalier de Valenciennes (E. Le Rhun), CHU Carémeau (C. Campello)

Germany: Universitaetsklinikum Dresden (D. Krex), Knappschaftskrankenhaus Bochum-Langendreer (U. Schlegel), LMU München - Klinikum Großhadern Neurochirurgische Klinik und Poliklinik (O. Schnell, J.C. Tonn), Universitaetsklinikum Freiburg (A. Weyerbrock), Charitè - Universitaetsmedizin Berlin (P. Vajkoczy), Universitaetsklinikum Bonn (U. Herrlinger), Klinikum der J.W. Goethe Universitaet Frankfurt (J.P. Steinbach), Universitaetsklinikum Heidelberg (W. Wick), Universitaetsklinikum Regensburg (P. Hau),

Universitaetsklinikum Ulm (T. Wiegel), Sozialstiftung Bamberg (P. Rieckmann), University Wuerzburg (G. Vince), Universitaetsklinikum Leipzig (R.D. Kortmann), Klinikum Nuernberg (J. Birkmann), Klinikum rechts der Isar TU Muechen (F. Schmidt), Universitaetsklinikum Magdeburg (G. Gademann), Universitaetsklinikum Schleswig-Holstein (H.M. Mehdorn), Universitaetsklinikum Goettingen (V. Rohde), Katharinenhospital (N. 
Hopf), Universitaetsklinikum Hamburg-Eppendorf (O. Heese), Klinikum der Universität Köln (R. Goldbrunner). Vivantes-Klinikum Neukoelln (M. de Wit), Universitaetsklinikum Essen (W. Sauerwein)

Hong Kong: Queen Mary Hospital (J. Tsang), Tuen Mun Hospital (C.H. Wong)

Hungary: Debreceni Egyetem Orvos- es Egeszsegtudomanyi Centrum (J. Szanto), Borsod-Abauj-Zemplen Megyei Korhaz es Egyetemi Oktato Korhaz (C. Olah), Szegedi Tudomanyegyetem (L. Thurzo), Kaposi Mor Oktato Korhaz (K. Pali)

India: Ruby Hall Clinic Services Pvt. Ltd (A.B. Bhanage), Apollo Speciality Hospital (P. Mahadev), Indraprastha Apollo Hospital (G.K. Jadhav), Bangalore Institute of Oncology (N. Rao), ACTREC - Tata Memorial Center (T. Gupta)

Israel: Haddasah Ein Kerem M.C (T. Siegal), Rambam Health Care Campus (T. Tzuk), Chaim Sheba Medical Center (A. Taliansky), Tel-Aviv Sourasky Medical Center (D. Blumenthal), Rabin M.C (Y. Kundel)

Italy: Ospedale Bellaria (A. Brandes), IRCCS Istituto Nazionale Tumori "Regina Elena" (C. Carapella), Istituto Scientifico Ospedale San Raffaele (M. Reni), Fondazione IRCCS (A. Silvani), Ospedali Civili di Brescia (M. Scerrati), Istituto Clinico Humanitas (A. Santoro), Policlinico di Modena (P.F. Conte), Azienda Sanitaria Ospedaliera S. Giovanni Battista-Le Molinette (R. Soffietti), Ospedali Civili di Brescia (S.M. Magrini), Presidio Ospedaliero Marconi Bufalini (M. Faedi), Università degli studi-Policlinico Careggi (G. Biti), IRCCS Ospedale Busonera (V. Zagonel)

Netherlands: VU Medisch Centrum (J. Buter), Erasmus MC-Daniel den Hoed (M.J vd Bent), Medisch Centrum Haaglanden (M.J.B. Taphoorn), St. Elizabeth Ziekenhuis (L.V. Beerepoot)

Poland: Centrum Onkologii (A. Kawecki), Centrum Onkologii - Instytut Oddział w Gliwicach (R. Tarnawski), Akademickie Centrum Kliniczne Szpital AM w Gdansku (J. Jassem), Centrum Onkologii im. Prof. F. Lukaszczyka w Bydgoszczy (K. Roszkowski), ZOZ MSWiA (S. Nawrocki), Wojewódzki Szpital Specjalistyczny im. M. Kopernika w Łodzi (J. Fijuth), Wielkopolskie Centrum Onkologii (K. Adamska), Beskidzkie Centrum Onkologii (D. Imielska-Zdunek), Dolnoslaskie Centrum Onkologii (A. Maciejczyk), Specjalistyczny Szpital im. dr A. Sokolowskiego (I. Wlodarska-Polinska), Centrum Onkologii Ziemi Lubelskiej (M. Mazurkiewicz)

Serbia: Clinical Hospital Center Zemun (I. Berisavac), Institute for Neurosurgery - Clinical Center Serbia (D. Grujicic)

Singapore: National Neuroscience Institute (E. Wang), National University Hospital (N. Chou)

Slovakia: Onkologicky ustav svatej Alzbety (S. Spanik), Fakultna NsP Bratislava - Nemocnica akad. L. Derera (P. Kalina), Vychodoslovensky onkologicky ustav a.s (P. Dubinsky), Fakultná nemocnica s poliklinikou F. Roosevelta (V. Malec), Narodny onkologicky ustav (I. Koza)

South Korea: Asan Medical Center (J.H. Kim), Catholic University of Korea - Seoul St. Marys Hospital (Y.K. Hong), Korea Cancer Center Hospital (C.H. Rhee), Seoul National University Bundang Hospital (C.Y. Kim), Severence Hospital - Yonsei University College of Medicine (J.H. Chang Hun), Samsung Medical Center (D.H. Nam) 
Spain: Hospital Clinic i Provincial (N. Vinolas), Hospital Universitario La Fe (G. Reynes), Hospital Vall d'Hebron (J. Rodon), Hospital Universitario La Paz (C. Belda), Hospital General de Valencia (A. Berrocal), Hospital Germans Trias i Pujol (C. Balaña), Hospital Clínico San Carlos Servicio de Oncología Planta Baja (P. Perez Segura), ICO-Institut Català d'Oncologia (S. del Barco), HGU de Elche (B. Sánchez)

Switzerland: Centre Hospitalier Universitaire Vaudois (R. Stupp), Inselspital - Universitätsspital Bern (A. Ochsenbein), UniversitätsSpital Zürich (M. Weller), Ospedale San Giovanni (G. Pesce), Kantonsspital Aarau (C. Mamot), Universitätsspital Basel (K. Conen), Kantonsspital St. Gallen (T. Hundsberger)

Taiwan: National Taiwan University Hospital (Y.K. Tu), Chi Mei Medical Center (C.C. Chio), Taichung Veterans General Hospital (C.C. Shen), Taipei Municipal WanFang Hospital (K.S. Hung), Chang-Gung Memorial Hospital - Linko (C.N. Chang)

United Kingdom: Clatterbridge Centre for Oncology (B. Haylock), Beatson West of Scotland Cancer Centre (A. James), Edinburgh Cancer Centre (S.C. Erridge), The Christie NHS FT (C. McBain), University College Hospital London (P. Mulholland), Aberdeen Royal Infirmary (D. Hurman)

USA: Duke University Medical Center (A. Desjardins), H. Lee Moffitt Cancer Center and Research Institute (E. Pan), Dartmouth-Hitchcock Medical Center (C. Fadul), University of Florida (E. Dunbar), Barrow Neurological Institute (L. Ashby), Baylor University Medical Center (K. Fink), The University of Tennessee (L.M. Michael), UC Davis Medical Center (R. Schrot), University of Washington School of Medicine (M. Mrugala), Henry Ford Health Systems (T. Mikkelsen), Washington University School of Medicine (K. Rich), Cedars-Sinai Medical Center (J. Rudnick), University of Rochester (N. Mohile), Case Medical Center (C. Nock), Columbia University Medical Center (R. Lai), Monmouth Medical Center (S. Raval), Wake Forest University Health Sciences (G. Lesser), Indiana University School of Medicine (E. Dropcho), Penn State Milton S. Hershey Medical Center (M. Glantz), Legacy Clinical Research \& Technology Center (J. Chen), St. Francis Medical Group Indianapolis (G. Smith), North Shore University Hospital (M. Schulder), St. Lukes Hospital (M. Salacz), Virginia Piper Cancer Institute (J. Trusheim), University of Alabama at Birmingham (L. Nabors), Emory University (A. Voloschin), The Ohio State University (H. Newton), Vanderbilt University Medical Center (P. Moots), Tisch Hospital Center - New York University School of Medicine (D. Gruber), Langone Medical Center (H. Krouwer), University of Nebraska Medical Center (P. Bierman), LAC-USC Medical Center (T. Chen), Mount Sinai School of Medicine (A. Demopoulos), Rhode Island Hospital (S. Jeyapalan), Tupelo Neurology Clinic (R. Maron) 